\title{
Choline-deficient High-fat Diet-induced Steatohepatitis in BALB/c Mice
}

\author{
Saut Horas Hatoguan Nababan', Seruni Tyas Khairunissa¹, Erni Erfan², Nafrialdi ${ }^{3}$, Ening Krisnuhoni ${ }^{4}$, \\ Irsan Hasan ${ }^{1}$, Rino Alvani Gani ${ }^{1}$ \\ ${ }^{1}$ Hepatobiliary Division, Internal Medicine Department, Faculty of Medicine, Universitas Indonesia, Cipto Mangunkusumo \\ General Hospital, Jakarta, Indonesia \\ ${ }^{2}$ Department of Oral Biology, Faculty of Dentistry, Universitas Trisakti, Jakarta, Indonesia \\ ${ }^{3}$ Department of Pharmacology and Therapeutics, Faculty of Medicine, Universitas Indonesia, Jakarta, Indonesia \\ ${ }^{4}$ Department of Pathology Anatomy, Faculty of Medicine, Universitas Indonesia, Cipto Mangunkusumo General Hospital, \\ Jakarta, Indonesia
}

Background: Non-alcoholic steatohepatitis (NASH) is an expanding cause of chronic liver disease worldwide, including Indonesia, with higher risk progression to cirrhosis and hepatocellular carcinoma. Preclinical experiments using several mice models have been conducted to clarify its complex pathogenesis. This study was designed to investigate whether $\mathrm{BALB} / \mathrm{c}$ mice on a choline-deficient high-fat diet can be used as a model for NASH.

Materials and Methods: BALB/c male mice were fed choline-deficient L-amino acid-defined high-fat diet (CDAHFD) or a standard diet for six weeks. The body and liver weights, liver histology, and plasma biochemistry were analyzed. The relative expression levels of tumor necrosis factor (TNF) $\alpha$, transforming growth factor (TGF) $\beta 1$, collagen-1 $\alpha 1$ (COL1 $\alpha 1$ ), glutathione peroxidase 1 (GPX1), and uncoupling protein 2 (UCP2) genes in the livers were analyzed using a two-step real time-polymerase chain reaction. Liver fatty acids composition was analyzed using gas chromatography with flame ionization detector (GC-FID).

Results: CDAHFD induced steatohepatitis in BALB/C mice with increased plasma levels of alanine aminotransferase. The liver of CDAHFD-fed BALB/c mice showed upregulated relative expression levels of TNF $\alpha$, TGF $\beta 1$, COL1 $\alpha 1$, GPX1, and UCP2 genes. The liver fatty acid analysis showed a significant accumulation of saturated fatty acids (SFAs) and an increased ratio of $n-6 / n-3$ polyunsaturated fatty acids (PUFAs) in the livers of CDAHFD-fed BALB/c mice.

Conclusion: This study suggests that CDAHFD can induce steatohepatitis in BALB/c mice and therefore may be used as NASH mice model.

Keywords: steatohepatitis, fatty liver, choline-deficient high fat diet, BALB/C

Date of submission: October 20, 2020

Last Revised: December 23, 2020

Accepted for publication: December 28, 2020

Corresponding Author:

Saut Horas Hatoguan Nababan

Hepatobiliary Division, Internal Medicine Department

Faculty of Medicine

Universitas Indonesia/Cipto Mangunkusumo General Hospital

J. Diponegoro No. 71, Jakarta 10430, Indonesia

e-mail: sautnbbn83@gmail.com

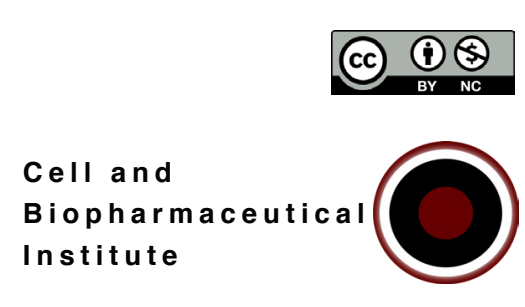




\section{Introduction}

Non-alcoholic steatohepatitis (NASH) represents a subset of non-alcoholic fatty liver disease (NAFLD) with significant liver inflammation with or without fibrosis. An increased number of NAFLD cases have been reported. ${ }^{1}$ In the urban population of Indonesia, the estimated prevalence of NAFLD is about $30 \% .^{2}$ While patients with simple steatosis have a better long term prognosis, NASH patients, on the other hand, have a higher risk of liver cirrhosis, hepatocellular carcinoma, cardiovascular complications, and extrahepatic malignancy. ${ }^{3}$ Currently, the multiple hit process hypothesis suggests that multiple factors can act in parallel in causing liver injury in NASH. These factors include genetic, mitochondrial dysfunction, endoplasmic reticulum stress, oxidative stress, altered adipokines/ cytokines, and gut dysbiosis. ${ }^{4}$

Mice models have been extensively used in understanding NASH pathogenesis, developing diagnostic biomarkers as well as identifying novel treatment targets. Using certain types of diet, different strains of mice show different susceptibility to develop NASH with different metabolic features. For example, under the long-term highfat diet the C57BL/6J mice developed NASH with obesity and insulin resistance, while the rapid onset of NASH could be induced using methionine-choline-deficient (MCD) or choline-deficient L-amino acid-defined diet (CDAA). ${ }^{5,6}$ Compared to C57BL/6J mice, BALB/c mice showed less liver inflammation and fibrosis under the MCD or highfat diet. ${ }^{7,8}$ On the other hand, unlike MCD diet, cholinedeficient L-amino acid-defined high-fat diet (CDAHFD) could also induce steatohepatitis in $\mathrm{C} 57 \mathrm{BL} / 6 \mathrm{~J}$ and $\mathrm{db} /$ $\mathrm{db}$ mice without losing bodyweight. ${ }^{9,10}$ Our study aims to investigate whether dietary treatment with CDAHFD could induce steatohepatitis in BALB/c mice. In this study, we examined liver histopathology, relative expression levels of inflammation, fibrosis, and oxidative stress-related genes as well as the liver fatty acids composition in CDAHFD-fed $\mathrm{BALB} / \mathrm{c}$ mice.

\section{Materials and methods}

\section{Ethical Approval}

All animal handling and treatments were carried out according to the animal experimentation regulation of Animal Research Facility of Indonesian Medical Education and Research Institute (IMERI), Faculty of Medicine,
Universitas Indonesia following international standard for animal care. ${ }^{11}$ The protocol for the animal experiments was approved by the Research Ethics Committee of the Faculty of Medicine, Universitas Indonesia (No. ND-265/UN2.F1/ ETIK/PPM.00.02/2019).

\section{Animal Experiment}

The animal experiment was conducted at the Animal Research Facility of Indonesian Medical Education and Research Institute (IMERI), Faculty of Medicine, Universitas Indonesia. BALB/c male mice (20-25 g) were acquired from PT. Bio Farma (Bandung, Indonesia) and allowed to acclimatize for one week before commencing the experiments. The mice were housed in individually ventilated cages at constant room temperature, $60 \%$ relative humidity, and a 12-hour light/dark cycle. The six-weekold mice were randomly divided into two experimental groups ( $\mathrm{n}=6$ each group). Animals were fed for six weeks with either standard diet or CDAHFD $(60 \% \mathrm{kcal}$ fat, 0,1\% methionine; \#A06071313, Research Diets Inc, New Brunswick, NJ, USA). The mice were allowed free access to food and water during experiments. Every week, the mice body weights were recorded. At the end of dietary treatment, after overnight fasting, the mice were euthanized by exsanguination under ketamine anesthesia. Whole blood samples were collected by cardiac puncture into tubes containing heparin and then centrifuged at $6,000 \mathrm{~g}$ for 10 min at $4^{\circ} \mathrm{C}$ to get plasma samples. Plasma samples were then stored at $-80^{\circ} \mathrm{C}$. The liver was perfused with distilled water before it was removed and weighed. Some parts of the liver tissue were fixed in $10 \%$ formalin buffer, and the rest were stored at $-80^{\circ} \mathrm{C}$.

\section{Liver Histology}

The formalin-fixed liver tissues were embedded in paraffin and then sectioned and stained with hematoxylin and eosin (H\&E).

\section{Plasma Biochemistry Analyses}

The plasma alanine aminotransferase (ALT), triglyceride, and total cholesterol levels of the mice were measured using commercial kits (Cobas, Roche, Basel, Switzerland).

\section{RNA Isolation and Two-Step Real-time PCR Relative Quantitation}

Total RNA was extracted from mice liver tissue with QIAamp RNA Blood Mini Kit (Qiagen, Hilden, Germany) 
and quantified using an ultraviolet spectrophotometer (NanoDrop 2000, Thermo Scientific, Waltham, MA, USA). Following the extraction procedure, the RNA template was treated with the QuantiTect Reverse Transcription Kit (Qiagen) to eliminate contaminating genomic DNA and cDNA synthesis. The amplification reactions were performed using the Quantitect SYBR Green PCR Kit (Qiagen) and analyzed using the 7500 real-time polymerase chain reaction (PCR) system (Applied Biosystem, Foster City, CA, USA). The sequences of the primers used for the PCR are listed in Table 1. The PCR cycling protocol was as follows: $95^{\circ} \mathrm{C}$ for $15 \mathrm{~min}, 40$ cycles of $94^{\circ} \mathrm{C}$ for $15 \mathrm{sec}, 58^{\circ} \mathrm{C}$ for $30 \mathrm{sec}$, and $72^{\circ} \mathrm{C}$ for $30 \mathrm{sec}$, followed by $72^{\circ} \mathrm{C}$ for $3 \mathrm{~min}$. The melting curve analysis was performed to verify the amplification product after the PCR cycling. The relative expression levels of all genes were quantified using the 2- $\Delta \Delta \mathrm{Ct}$ method with each gene normalized to glyceraldehyde 3-phosphate dehydrogenase (GAPDH).

\section{Gas chromatography with Flame Ionization Detector (GC-FID)-based Fatty Acids Analysis}

Fatty acids in the mice liver tissue samples were analyzed using Agilent Technologies 6890 gas chromatograph with autosampler and flame ion detector and chem-station data system. First, $75 \mu \mathrm{L}$ internal standard (Tridecanoic acid and Heptadecanoic acid) and $2 \mathrm{~mL} 6 \mathrm{M} \mathrm{HCL}$ in methanol (5:1) were added into $100 \mathrm{mg}$ frozen liver tissue samples and then incubated for 4 hours at $90-100^{\circ} \mathrm{C}$ oven. Next, the samples were kept on ice for $5 \mathrm{~min}$. Then, $4 \mathrm{~mL}$ of hexane were added and samples were mixed for $10 \mathrm{~min}$. After being centrifuged for $10 \mathrm{~min}$, the organic layers were collected and vaporized at $25^{\circ} \mathrm{C}$ until dried. Then, $200 \mu \mathrm{L}$ of hexane were added before analysis, and $5 \mu \mathrm{L}$ of samples were injected. The sample injector was initially held at $120^{\circ} \mathrm{C}$ for $5 \mathrm{~min}$, rising at $5^{\circ} \mathrm{C} / \mathrm{min}$ to $220^{\circ} \mathrm{C}$, held for $5 \mathrm{~min}$, and finally rising $4^{\circ} \mathrm{C} / \mathrm{min}$ to $240^{\circ} \mathrm{C}$ and held for $10 \mathrm{~min}$. Helium was used as the carrier gas and the column flow rate was $1.5 \mathrm{~mL} / \mathrm{min}$.

\section{Statistical Analysis}

The significance of differences was analyzed using the Student's t-test. A $p$-values of $<0.05$ were regarded as statistically significant. Unless stated otherwise, all data were presented as the mean \pm standard error of the mean (SEM).

\section{Results}

\section{CDAHFD-induced Steatohepatitis in $B A L B / c$ Mice}

In standard diet-fed BALB/c mice, liver histology showed normal lobular architecture with minimal inflammatory cells without making any structural changes. Compared to the standard diet, CDAHFD feeding for six weeks induced steatosis, lobular inflammatory infiltrates, and ballooning in the liver tissue of BALB/c mice. Steatosis was characterized by hepatomegaly and an increase in liver tissue weight (Figure 1). The presence of inflammatory cells in the liver would cause liver injury, which was characterized by an increase in plasma ALT levels (Table 2). In this study, $\mathrm{BALB} / \mathrm{c}$ mice fed the CDAHFD showed an increase in body weight after six weeks. Triglyceride and total cholesterol plasma levels were lower in the group that received CDAHFD.

Inflammation, Fibrosis, and Oxidative Stress-related Genes Expression

CDAHFD-fed BALB/c mice showed significantly higher liver relative expression levels of tumor necrosis factor (TNF) $\alpha$, transforming growth factor (TGF) $\beta 1$ and collagen$1 \alpha 1$ (COL1 $\alpha 1)$ genes (Figure 2). To evaluate liver oxidative stress, we also measured the liver relative expression levels of glutathione peroxidase-1 (GPx1) and uncoupling

Table 1. Primer sequences used for RT-PCR.

\begin{tabular}{|c|c|c|}
\hline Gene & Forward Primer (5'-3') & Reverse Primer (5'-3') \\
\hline \multicolumn{3}{|l|}{ Mice } \\
\hline $\mathrm{TNF} \alpha$ & $5^{\prime}$-tggcccagaccctcacactcag-3' & 5'-ggtggtttgctacgacgtgggc-3' \\
\hline TGF $\beta 1$ & 5'-tgagtggctgtcttttgacg-3' & 5'-agtgagcgctgaatcgaaag-3' \\
\hline COL1 $1 \alpha 1$ & 5'-tcgagctcagaggcgaaggca-3' & $5^{\prime}$-ggtgtgactcgtgcagccgt-3' \\
\hline $\mathrm{UCP} 2$ & 5'-tacaaggggttcatgccttc-3' & 5'-attggtaggcagccattagg-3, \\
\hline GPx1 & 5'-ggacaccaggagaatggcaa-3' & 5 '-gtaaagagcgggtgagectt-3' \\
\hline GAPDH & $5^{\prime}$-aaatggtgaaggtcggtgtg-3' & $5^{\prime}$-aatctccactttgccactgc-3' \\
\hline
\end{tabular}



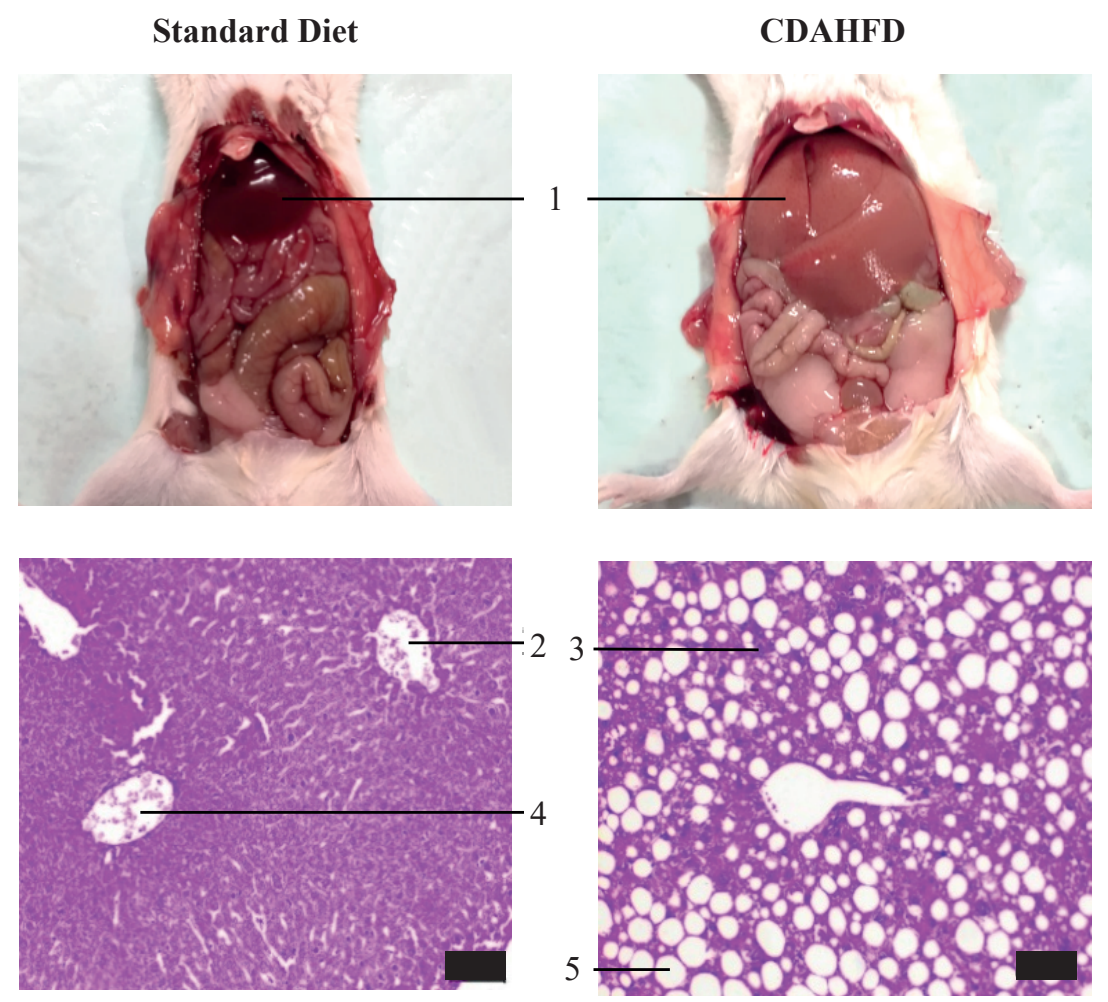

Figure 1. Representative liver macroscopic and histopathological features of $B A L B / c$ mice fed standard diet or CDAHFD for 6 weeks. 1: liver, 2: central vein, 3: inflammatory cells, 4: portal vein, 5: macrovesicular steatosis. Liver tissues were stained with H\&E staining. Black bar: $100 \mu \mathrm{m}$.

protein-2 (UCP2) genes. Compared to standard diet-fed BALB/c mice, CDAHFD feeding induced significantly higher relative expression levels of GPx1 and UCP2 genes.

\section{Liver Fatty Acids Composition}

In general, we found that all fatty acids detected were upregulated significantly in liver tissue of CDAHFD-fed BALB/c mice, except for gamma-linolenic acid (C18:3n6) and behenic acid (C22:0). The level of saturated fatty acids (SFAs) such as arachidic acid (C20:0), lignoceric acid (C24:0), followed by myristic acid (C14:0), palmitic acid (C16:0), and stearic acid (C18:0) were significantly higher in the livers of CDAHFD-fed BALB/c compared to those fed with the standard diet. The ratio of $n-6 / n-3$ polyunsaturated fatty acid (PUFAs) was significantly increased in liver tissue of CDAHFD-fed BALB/c mice (Table 3).

Table 2. Metabolic features of BALB/c mice fed the standard diet or CDAHFD at 6 weeks.

\begin{tabular}{lcc}
\hline \multirow{2}{*}{ Diet } & \multicolumn{2}{c}{ Mean \pm SEM } \\
\cline { 2 - 3 } & Standard Diet & CDAHFD \\
\hline Bodyweight (gr) & $37.16 \pm 1.13$ & $37.50 \pm 0.99$ \\
$\quad$ Initial & $45.33 \pm 1.97$ & $40.5 \pm 0.62^{*}$ \\
$\quad$ Final & $4.83 \pm 0.40$ & $6.16 \pm 0.30^{*}$ \\
Liver weight (gr) & $41.16 \pm 3.24$ & $546.83 \pm 97.17^{*}$ \\
ALT (mg/dL) & $128.50 \pm 25.18$ & $68.50 \pm 8.72^{*}$ \\
Triglyceride (mg/dL) & $88.16 \pm 5.02$ & $41.33 \pm 8.11^{*}$ \\
Total cholesterol (mg/dL) &
\end{tabular}

Data are shown as the mean $\pm \operatorname{SEM}(\mathrm{n}=6)$. ${ }^{*} p<0.05$ compared with the SDfed BALB/c mice. 


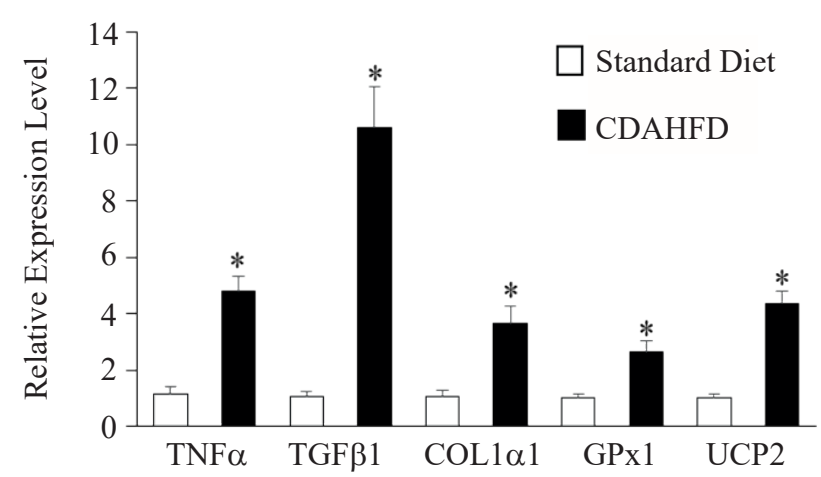

Figure 2. Relative expression levels of inflammation, fibrosis, and oxidative stress-related genes in the livers of $B A L B / c$ mice fed the standard diet or CDAHFD for 6 weeks. Relative expression levels were determined using RT-PCR. GAPDH was used as an endogenous control. Data are shown as the mean $\pm \operatorname{SEM}(\mathrm{n}=6) .{ }^{*} p<0.05$ compared with the SD-fed BALB/c mice.

\section{Discussion}

Preferably, a NASH mice model should display similar liver pathology with human NASH along with its common metabolic risk factors such as obesity or diabetes mellitus. In this study, we found that BALB/c mice developed steatohepatitis with weight gain after 6 weeks of CDAHFD. The CDAHFD-induced steatohepatitis in our BALB/c mice was characterized by increased liver inflammatory and fibrosis cytokines as well as oxidative stress-related gene expressions. Furthermore, the steatohepatitis in CDAHFDfed BALB/c mice was associated with the accumulation of liver SFAs and an increased ratio of n-6/n-3 PUFAs.

Several strains of mice showed different susceptibility to the development of NASH. BALB/c male mice showed greater liver lipid accumulation after 9 weeks of high-fat diet compared to $\mathrm{C} 57 \mathrm{BL} / 6 \mathrm{~J}$ male mice of the same age. ${ }^{12}$ However, under a methionine-choline-deficient diet, which is widely used for inducing steatohepatitis, BALB/c mice developed less severe steatohepatitis compared to C57BL/6J mice after 4 weeks of feeding. This could be related to differences in Th1/Th2-type immune response, macrophage activation pattern, and immune response to oxidative stress-derived antigens. ${ }^{7,8,13}$ Previously, CDAHFD induced steatohepatitis and fibrosis in C57BL/6J mice and $\mathrm{db} / \mathrm{db}$ mice. ${ }^{9,10}$ Similar to the previous studies, CDAHFD also rapidly induced steatohepatitis in our BALB/c mice after six weeks. We also confirmed that $0.1 \%$ methionine in
CDAHFD could provide a stable body weight condition for the development of steatohepatitis in our BALB/c mice. ${ }^{14}$ Choline deficiency may cause the impaired synthesis of phosphatidylcholine and secretion of very-low-density lipoprotein (VLDL). ${ }^{15}$ This could cause low levels of triglyceride and total cholesterol in our CDAHFD-fed $\mathrm{BALB} / \mathrm{c}$ mice.

Supporting the steatohepatitis phenotype, we found increased relative expression levels of $\mathrm{TNF} \alpha$ in the liver. $\mathrm{TNF} \alpha$ is an important inflammatory mediator in the pathogenesis of NASH. Increased TNF $\alpha$ level has been reported in the liver and plasma of NASH patients and correlated with liver fibrosis. ${ }^{16,17}$ TNF $\alpha$ inhibition using pentoxifylline improved liver inflammation in human NASH. ${ }^{18}$ In our CDAHFD-fed BALB/c mice, we found increased fibrogenic signaling as evidenced by significantly higher liver relative expression levels of TGF $\beta 1$ and COL $1 \alpha 1$. Increased hepatic TGF $\beta 1$ has been reported in human NASH. ${ }^{19}$ In advanced NASH, TGF $\beta 1$ induces hepatic stellate cell activation and differentiation into myofibroblast phenotype and collagen deposition. ${ }^{20}$ Furthermore, the previous study showed that TGF $\beta 1$ also induced steatohepatitis through induction of lipogenesis, suppression of $\beta$-oxidation related genes, and reactive oxygen species (ROS) production in hepatocytes. ${ }^{21}$

In this study, CDAHFD-fed BALB/c mice showed upregulation of GPx1, an antioxidant enzyme, indicating an enhanced production of ROS in the liver. Glutathione peroxidase is found abundant in the liver and catalyzes the conversion of hydrogen peroxide $\left(\mathrm{H}_{2} \mathrm{O}_{2}\right)$ to $\mathrm{H}_{2} \mathrm{O}$. Increased expression levels of GPx1 had been reported in other NASH mice model. ${ }^{22,23}$ Increased activity of glutathione peroxidases also reported in NAFLD patients. ${ }^{24}$ Enhanced ROS production in our NASH model might cause mitochondria proton leakage due to increased expression of UCP2, leading to impairment of mitochondria oxidative phosphorylation and depletion of liver adenosine triphosphate (ATP) content. Liver UCP2 overexpression had been reported in experimental and human NASH. ${ }^{25}$ ROS could induce the synthesis of TNF $\alpha$ by hepatocyte, which triggers hepatocyte apoptosis and necrosis. ${ }^{26}$ On the other hand, $\mathrm{TNF} \alpha$ could impair the mitochondria respiratory chain further increase mitochondrial ROS production. All of these processes could drive liver injury in our CDAHFDfed BALB/c mice.

Besides inflammation and oxidative stress, lipotoxicity due to the accumulation of fatty acids, also contribute to 
Table 3. Fatty acid contents in the livers of BALB/c mice fed the standard diet or CDAHFD for 6 weeks.

\begin{tabular}{|c|c|c|c|c|c|c|}
\hline \multirow[b]{2}{*}{ Fatty Acids } & \multicolumn{2}{|c|}{ Standard Diet } & \multicolumn{2}{|c|}{ CDAHFD } & \multirow[b]{2}{*}{ Fold Change } & \multirow[b]{2}{*}{$p$-value* } \\
\hline & $\begin{array}{c}\text { Mean } \\
(\mathrm{mg} / \mathrm{mL})\end{array}$ & SEM & $\begin{array}{c}\text { Mean } \\
(\mathrm{mg} / \mathrm{mL})\end{array}$ & SEM & & \\
\hline C 14:0 & 0.024 & 0.002 & 0.171 & 0.014 & 7.118 & $<0.001$ \\
\hline C 16:0 & 2.777 & 0.527 & 9.173 & 0.617 & 3.303 & $<0.001$ \\
\hline C $16: \ln 9$ & 0.131 & 0.011 & 0.368 & 0.036 & 2.82 & 0.001 \\
\hline C 18:0 & 1.978 & 0.137 & 4.004 & 0.293 & 2.025 & $<0.001$ \\
\hline C $18: \ln 9$ & 1.982 & 0.261 & 15.061 & 1.021 & 7.598 & $<0.001$ \\
\hline C $18: 2 \mathrm{n} 6$ & 1.987 & 0.158 & 10.892 & 0.73 & 5.482 & $<0.001$ \\
\hline C $18: 3 n 6$ & 0.032 & 0.003 & 0.024 & 0.001 & 0.743 & 0.025 \\
\hline C 20:0 & 0.023 & 0.001 & 0.374 & 0.029 & 15.99 & $<0.001$ \\
\hline C $18: 3 n 3$ & 0.058 & 0.006 & 0.474 & 0.042 & 8.154 & $<0.001$ \\
\hline C 20:1 & 0.028 & 0.008 & 0.091 & 0.009 & 3.294 & $<0.001$ \\
\hline C 20:3n6 & 0.019 & 0.002 & 0.028 & 0.002 & 1.491 & 0.002 \\
\hline C 22:0 & 2.442 & 0.158 & 3.021 & 0.217 & 1.237 & 0.059 \\
\hline C $20: 4 n 6$ & 0.147 & 0.011 & 0.349 & 0.019 & 2.371 & $<0.001$ \\
\hline C 20:5n3 & 0.968 & 0.067 & 1.887 & 0.154 & 1.949 & 0.001 \\
\hline C 24:0 & 0.028 & 0.001 & 0.372 & 0.121 & 13.169 & 0.036 \\
\hline C 24:1 & 0.095 & 0.012 & 0.168 & 0.026 & 1.772 & 0.035 \\
\hline C 22:6n3 & 0.075 & 0.006 & 0.096 & 0.004 & 1.283 & 0.022 \\
\hline$\Delta \mathrm{n}-6$ & 2.185 & 0.17 & 11.293 & 0.735 & 5.168 & $<0.001$ \\
\hline$\Delta \mathrm{n}-3$ & 1.101 & 0.076 & 2.456 & 0.178 & 2.231 & $<0.001$ \\
\hline$\Delta n-6 / \Delta n-3$ & 1.981 & 0.036 & 4.639 & 0.233 & 2.342 & $<0.001$ \\
\hline
\end{tabular}

Liver fatty acids composition was measured as described in the Materials and Methods section. Data are shown as the mean $\pm \operatorname{SEM}(\mathrm{n}=6)$. *Tested with Student's t-test.

NASH progression. In our study, we found increased levels of liver SFAs, such as myristic acid (C14:0), palmitic acid (C16:0), stearic acid (C18:0), arachidic acid (C20:0), and lignoceric acid (C24:0). Increased levels of SFAs have been reported in NASH patients. ${ }^{27,28}$ SFAs itself could cause liver injury through activation of the inflammasome, production of pro-inflammatory cytokines, endoplasmic reticulum stress, ROS accumulation, and apoptosis. ${ }^{29-32}$ The liver PUFAs n-6/n-3 ratio was higher in human NASH, as previously reported. ${ }^{27} \mathrm{We}$ also found similar findings in our CDAHFD-fed BALB/c mice model. In particular, we found that the liver content of 18:2n6 (linoleic acid) and 20:4n6 (arachidonic acid) increased significantly in CDAHFD-fed $\mathrm{BALB} / \mathrm{c}$ mice. Linoleic acid is a precursor of arachidonic acid (20:4n6), which can be converted into pro-inflammatory prostaglandin, leukotrienes, and thromboxanes. An in vitro study showed that linoleic acid could induce endoplasmic reticulum stress and apoptosis..$^{33}$ Increased oxidized linoleic acid due to oxidative stress in the liver could increase TNF $\alpha$ synthesis by Kupffer cells. ${ }^{34}$ The previous study showed that substituting dietary linoleic acid with alpha-linolenic acid or long-chain n-3 PUFAs could decrease liver inflammation and oxidative stress in the Western diet-induced steatohepatitis model. $^{35}$

Metabolic disorders, such as obesity, hyperlipidemia, or type 2 diabetes mellitus are closely linked to disease progression in NAFLD. Recently, a new term of metabolic dysfunction-associated fatty liver disease (MAFLD) has been proposed to define fatty liver in the presence of these metabolic complications. ${ }^{36}$ Our study showed that CDAHFD-fed BALB/c mice didn't suffer from hyperlipidemia or marked obesity. Nevertheless, NAFLD has also been reported in lean, non-obese patients. ${ }^{37}$ Therefore, our CDAHFD-fed BALB/c mice could serve as a model to understand the pathogenesis of steatohepatitis, independent of hyperlipidemia or obesity. 


\section{Conclusion}

In summary, we confirmed that CDAHFD induces steatohepatitis in $\mathrm{BALB} / \mathrm{c}$ mice which are characterized by increased expression levels of pro-inflammatory, profibrotic cytokines, and oxidative stress. These may be caused by lipotoxicity due to the accumulation of liver SFAs and increased PUFAs n-6/n-3 ratio.

\section{Acknowledgments}

We thank Mrs. Ernawati from Jakarta Regional Health Laboratory for the technical assistance and all of the members of our hepatobiliary division for their suggestions during preparations of this manuscript. We also thank the Ministry of Research and Technology/ National Research and Innovation Agency Republic of Indonesia for providing the financial support for the conduct of this research (NKB176/UN2.RST/HKP.05.00/2020).

\section{References}

1. Younossi ZM, Koenig AB, Abdelatif D, Fazel Y, Henry L, Wymer M. Global epidemiology of nonalcoholic fatty liver diseasemeta-analytic assessment of prevalence, incidence, and outcomes. Hepatology. 2016; 64(1): 73-84.

2. Amarapurkar DN, Hashimoto E, Lesmana LA, Sollano JD, Chen $\mathrm{PJ}$, Goh KL, et al. How common is non-alcoholic fatty liver disease in the Asia-Pacific region and are there local differences? J Gastroenterol Hepatol. 2007; 22(6): 788-93.

3. Byrne CD, Targher G. NAFLD: a multisystem disease. J Hepatol. 2015; 62(1 Suppl): S47-64.

4. Caligiuri A, Gentilini, A, Marra, F. Molecular pathogenesis of NASH Int J Mol Sci. 2016; 17(1575): 1-34. doi: 10.3390/ijms17091575.

5. Ito M, Suzuki J, Tsujioka S, Sasaki M, Gomori A, Shirakura T, et al. Longitudinal analysis of murine steatohepatitis model induced by chronic exposure to high-fat diet. Hepatol Res. 2007; 37(1): 50-7.

6. Van Herck MA, Vonghia L, Francque SM. Animal models of nonalcoholic fatty liver disease - a starter's guide. Nutrients. 2017; 9(10): 1072. doi: 10.3390/nu9101072.

7. Maina V, Sutti S, Locatelli I, Vidali M, Mombello C, Bozzola C, et $a l$. Bias in macrophage activation pattern influences non-alcoholic steatohepatitis (NASH) in mice. Clin Sci (Lond). 2012; 122(11): 545-53.

8. Jovicic N, Jeftic I, Jovanovic I, Radosavljevic G, Arsenijevic N, Lukic ML, et al. Differential immunometabolic phenotype in Th1 and Th2 dominant mouse strains in response to high-fat feeding. PLoS One. 2015; 10 (7): e0134089. doi: 10.1371/journal.pone.0134089.

9. Nababan SHH, Nishiumi S, Kawano Y, Kobayashi T, Yoshida M, Azuma T. Adrenic acid as an inflammation enhancer in nonalcoholic fatty liver disease. Arch Biochem Biophys. 2017; 623624: 64-75.

10. Matsumoto M, Hada N, Sakamaki Y, Uno A, Shiga T, Tanaka C, et $a l$. An improved mouse model that rapidly develops fibrosis in nonalcoholic steatohepatitis. Int J Exp Pathol. 2017; 94(2): 93-103.
11. National Research Council. Guide for the Care and Use of Laboratory Animals: Eighth Edition. Washington DC: The National Academies Press; 2011.

12. Nishikawa S, Yasoshima A, Doi K, Nakayama H, Uetsuka K. Involvement of sex, strain and age factors in high fat diet-induced obesity in C57BL/6J and BALB/cA mice. Exp. Anim. 2007; 56(4): 263-272.

13. Maina V, Sutti S, Vidali M, Bozzola C, Mombello C, Boldorini R, et al. Strain differences in mice susceptibility to steatohepatitis induced by methionine/choline deficient diet underscore a role of immune mechanism in NASH. J Hepatol. 2010; 52 (Supplement 1): S308. doi: 10.1016/S0168-8278(10)60795-7.

14. Chiba T, Suzuki S, Sato Y, Itoh T, Umegaki K. Evaluation of methionine content in a high-fat and choline-deficient diet on body weight gain and the development of non-alcoholic steatohepatitis in mice. PLoS One. 2016;11(10): e0164191. doi: 10.1371/journal. pone. 0164191

15. Macfarlane DP, Zou X, Andrew R, Morton NM, Livingstone DEW, Aucott RL, et al. Metabolic pathways promoting intrahepatic fatty acid accumulation in methionine and choline deficiency: implications for the pathogenesis of steatohepatitis. Am J Physiol Endocrinol Metab. 2011; 300(2): E402-9.

16. Lesmana CR, Hasan I, Budihusodo U, Gani RA, Krisnuhoni E, Akbar $\mathrm{N}$, et al. Diagnostic value of a group of biochemical markers of liver fibrosis in patients with non-alcoholic steatohepatitis. J Dig Dis. 2009; 10(3): 201-6.

17. Stojsavljević S, Palčić MG, Jukić LV, Duvnjak LS, Duvnjak M. Adipokines and proinflammatory cytokines, the key mediators in the pathogenesis of nonalcoholic fatty liver disease. World $\mathrm{J}$ Gastroenterol. 2014; 20(48): 18070-91

18. Du J, Ma YY, Yu CH, Li YM. Effects of pentoxifylline on nonalcoholic fatty liver disease: a meta-analysis. World J Gastroenterol. 2014; 20(2): 569-77.

19. Cayón A, Crespo J, Mayorga M, Guerra A, Pons-Romero F. Increased expression of $\mathrm{Ob}-\mathrm{Rb}$ and its relationship with the overexpression of TGF-beta1 and the stage of fibrosis in patients with nonalcoholic steatohepatitis. Liver Int. 2006; 26(9): 1065-71.

20. Sircana A, Paschetta E, Saba F, Molinaro F, Musso G. Recent insight into the role of fibrosis in nonalcoholic steatohepatitis-related hepatocellular carcinoma. Int J Mol Sci. 2019; 20(7): 1745. doi: 10.3390/ijms20071745.

21. Yang L, Roh YS, Song J, Zhang B, Liu C, Loomba R, et al. TGF- $\beta$ signaling in hepatocytes participates in steatohepatitis through regulation of cell death and lipid metabolism. Hepatology. 2014; 59(2): 483-95.

22. Jarukamjorn K, Jearapong N, Pimson C, Chatuphonprasert W. A high-fat, high-fructose diet induces antioxidant imbalance and increases the risk and progression of nonalcoholic fatty liver disease in mice. Scientifica (Cairo). 2016; 2016: 5029414. doi: $10.1155 / 2016 / 5029414$

23. Ore A, Akinloye OA. Oxidative stress and antioxidant biomarkers in clinical and experimental models of non-alcoholic fatty liver disease. Medicina (Kaunas). 2019; 55(2): 26. doi: 10.3390/ medicina55020026.

24. Kumar A, Sharma A, Duseja A, Das A, Dhiman RK, Chawlaet YK, et al. Patients with nonalcoholic fatty liver disease (NAFLD) have higher oxidative stress in comparison to chronic viral hepatitis. J Clin Exp Hepatol. 2013; 3(1): 12-8.

25. Serviddio G, Bellanti F, Tamborra R, Rollo T, Capitanio N, Romano 
$\mathrm{AD}$, et al. Uncoupling protein-2 (UCP2) induces mitochondrial proton leak and increases susceptibility of nonalcoholic steatohepatitis (NASH) liver to ischaemia-reperfusion injury. Gut. 2008; 57(7): 957-65.

26. Mansouri A, Gattolliat $\mathrm{CH}$, Asselah T. Mitochondrial dysfunction and signaling in chronic liver diseases. Gastroenterology. 2018; 155(3): $629-47$.

27. Chiappini F, Coilly A, Kadar H, Gual P, Tran A, Desterke C, et al. Metabolism dysregulation induces a specific lipid signature of nonalcoholic steatohepatitis in patients. Sci Rep. 2017; 7(46658): 1-17. doi: 10.1038/srep46658.

28. Yamada K, Mizukoshi E, Sunagozaka H, Arai K, Yamashita T, Takeshita Y, et al. Characteristics of hepatic fatty acid compositions in patients with nonalcoholic steatohepatitis. Liver Int. 2015; 35(2): 582-90.

29. Csak T, Ganz M, Pespisa J, Kodys K, Dolganiuc A, Szabo G. Fatty acid and endotoxin activate inflammasomes in mouse hepatocytes that release danger signals to stimulate immune cells. Hepatology. 2011; 54(1): 133-44.

30. Feldstein AE, Werneburg NW, Canbay A, Guicciardi ME, Bronk SF, Rydzewski R, et al. Free fatty acids promote hepatic lipotoxicity by stimulating TNF $\alpha$ expression via a lysosomal pathway. Hepatology. 2004; 40(1): 185-94.

31. Joshi-Barve S, Barve SS, Amancherla K, Gobejishvili L, Hill D, Cave $\mathrm{M}$, et al. Palmitic acid induces production of proinflammatory cytokine interleukin-8 from hepatocytes. Hepatology. 2007; 46(3): 823-30.

32. Leamy AK, Egnatchik RA, Young JD. Molecular mechanisms and the role of saturated fatty acids in the progression of non-alcoholic fatty liver disease. Prog Lipid Res. 2013; 52(1): 165-74.

33. Zhang Y, Xue R, Zhang Z, Yang X, Shi H. Palmitic and linoleic acids induce ER stress and apoptosis in hepatoma cells. Lipids Health Dis. 2012; 11(1): 1-8. doi: 10.1186/1476-511X-11-1.

34. Böhm T, Berger H, Nejabat M, Riegler T, Kellner F, Kuttke M, et al. Food derived peroxidized fatty acids may trigger hepatic inflammation: a novel hypothesis to explain steatohepatitis. J Hepatol. 2013; 59(3): 563-70.

35. Jeyapal S, Kona SR, Mullapudi SV, Putcha UK, Gurumurthy P, Ibrahim A. Substitution of linoleic acid with $\alpha$-linolenic acid or long chain n-3 polyunsaturated fatty acid prevents Western diet induced nonalcoholic steatohepatitis. Sci Rep. 2018; 8 (10953): 1-14. doi: 10.1038/s41598-018-29222-y.

36. Eslam M, Newsome PN, Sarin SK, Anstee QM, Targher G, RomeroGomez $\mathrm{M}$, et al. A new definition for metabolic dysfunctionassociated fatty liver disease: An international expert consensus statement. J Hepatol. 2020; 73(1): 202-9.

37. Ye Q, Zou B, Yeo YH, Li J, Huang DQ, Wu Y, et al. Global prevalence, incidence, and outcomes of non-obese or lean nonalcoholic fatty liver disease: a systematic review and meta-analysis. Lancet Gastroenterol Hepatol. 2020; 5(8): 739-52. 